\section{References}

ALLISON, D., MENTORE, J. MOONSEONG, H., et al (1999) Antipsychotic-induced weight gain: a comprehensive research synthesis. American Journal of Psychiatry, 156, 1686-1696.

AMERICAN DIABETES ASSOCIATION, AMERICAN PSYCHIATRIC ASSOCIATION, AMERICAN ASSOCIATION OF CLINICAL ENDOCRINOLOGISTS, et al (2004) Consensus development conference on antipsychotic drugs and obesity and diabetes. Diabetes Care, 27, 596-601.

BRITISH MEDICAL ASSOCIATION \& ROYAL PHARMACEUTICAL SOCIETY OF GREAT BRITAIN (2006) British National Formulary (March issue). BMJ Books \& Pharmaceutical Press.
BROWN, S. (1997) Excess mortality of schizophrenia: a meta-analysis. British Journal of Psychiatry, 171, 502-508.

CACI/TNS (2006) Health of the Nation Report (http://www.caci.co.uk/ acorn/downloads/Health\%20 of $\% 20$ Nation\%20Report.pdf).

DISABILITY RIGHTS COMMISSION (2006) Equal Treatments: Closing the Gap. Disability Rights Commission.

EXPERT PANEL ON DETECTION, EVALUATION AND TREATMENT OF HIGH BLOOD CHOLESTEROL IN ADULTS (2001) Executive summary of the third report of the National Cholesterol Education Program (NCEP) Expert Pane on Detection, Evaluation and Treatment of High Blood Cholesterol in Adults (Adult Treatment Panel III). JAMA, 285, 2486-2497.
FENTON,W. \& CHAVEZ, M. (2006)

Medication induced weight gain and dyslipidaemia in patients with

schizophrenia. American Journal of Psychiatry, 163, 1697-1704.

KANE, J., HONIFELD, G., SINGER, J., et al (1988) Clozapine for the treatment resistant schizophrenic. Archives of General Psychiatry, 45, 789-796.

LAKKA, H., LAAKSONEN, D., LAKKA, T., et al (2002) The metabolic syndrome and total and cardiovascular disease mortality in middle aged men. JAMA 288, 2709-2716.

*David William Morgan Specialty Registrar (ST4) in Forensic Psychiatry, The Caswell Clinic, Glanrhyd Hospital, Tondu Road, Bridgend, South Wales CF314LN, email: davidw.morgan@bromor-tr.wales.nhs.uk, Matthew Paul Sargeant Medical Director and Consultant Psychiatrist, Jude Chukwuma Specialist Registrar in General Adult Psychiatry, Gwenllian Hughes Pharmacist, Carmarthenshire Locality, Pembrokeshire and Derwen NHS Trust, Hafan Derwen, Parc Dewi Sant, Carmarthen

\title{
Comparison of older people with psychosis living in the community and in care homes
}

\section{AIMS AND METHOD}

To compare two groups of older people with chronic schizophrenia or delusional disorder living in the community and in care homes, along the domains of morbidity suggested by prior research. From the case-load of one old age psychiatrist, 22 individuals with chronic psychosis residing in care homes were compared to 23 living in their own homes. The measures used were: the Positive and Negative Symptom Score (PANSS; Kay et al, 1987); the Mini Mental State
Examination (MMSE; Folstein et al, 1975); the Burvill Physical IIIness Scale (Burvill et al, 1990); and an Activities of Daily Living Scale (IADL; Lawton et al, 1969).

\section{RESULTS}

Those in care homes had significantly higher PANSS scores (38.9 v. 21.0, $P<0.01)$, largely accounted for by significantly more deficit symptoms (14.2 v. 5.6, $P<0.01$ ). They also had poorer cognition and significantly greater impairment in daily-life activities but their medical condition was not significantly worse. Most were seen only by a psychiatrist.

\section{CLINICAL IMPLICATIONS}

The greater morbidity and disablement of older people with chronic schizophrenia or delusional disorder living in care homes is likely to be intrinsic to the disorder but does not appear to be taken into account in current service planning or delivery.
The Royal College of Psychiatrists college report on individuals who enter old age with a psychosis such as chronic schizophrenia (Royal College of Psychiatrists, 2002) highlighted an unmet need in this area and recommended local surveys to address this. One, undertaken in a Scottish service (McNulty et al, 2003), found high levels of disability and significant unmet need among people with schizophrenia aged over 65 years old. These individuals are often admitted to care homes but it is not known in what way they differ from those who continue to reside in their own homes. Factors known to contribute to morbidity in late-life psychosis include level of psychiatric symptomatology, cognition, medical morbidity and disablement (Jolley et al, 2004). In a single catchment area we compared these domains in two groups of older people with either chronic schizophrenia or delusional disorder, one in care homes and the other living independently in the community. The hypothesis we wanted to test was whether or not those in care homes would have greater severity of psychiatric symptoms, more medical morbidity and poorer cognition than those living independently at home.

\section{Method}

Inclusion criteria were: aged over 65 years old, under the care of one psychiatrist (R.B.) who had a defined 
catchment area, a primary diagnosis of schizophrenia or delusional disorder according to ICD-10 criteria (World original papers Health Organization, 1993) and living in the community. People excluded from our study were those with a primary diagnosis of dementia or affective disorder, inpatients of acute in-patient psychiatric units and those who refused to take part. Mental capacity and consent was undertaken by R.B. Where a person lacked the capacity to give informed consent, their caregivers and/ or relatives were approached. The research was approved by the local research ethics committee and Manchester Mental Health and Social Care Trust was the sponsor of the study.

We used the Positive and Negative Symptom Score (PANSS), which assesses positive, negative and general psychotic symptomatology on a 30-point scale (Kay et al, 1987). Cognition was assessed using the Mini Mental State Examination (MMSE; Folstein et al, 1975) and dementia was diagnosed based on the ICD-10 criteria for dementia (World Health Organization, 1993). The Burvill Physical Illness Scale was used to quantify morbidity from physical illness (Burvill et al, 1990) and the Instrumental Activities of Daily Living Scale (IADL; Lawton et al, 1969) was used to assess self-maintenance ( 6 categories, rated 0 or 1 ) and more complex daily-life tasks (8 categories, rated 0 or 1). Interviews were conducted at the participant's residence in compliance with the Trust's safe visiting policy. Sources of information included the participant, caregivers and case notes.

The data was analysed using SPSS version 11.5 for Windows, with $\chi^{2}$-test for categorical data and t-test for continuous data.

\section{Results}

The inclusion criteria were met by 52 individuals. Four were excluded because they died or left the area before the study commenced, two refused to take part and one was diagnosed as having psychotic depression rather than schizophrenia. Forty-five patients were therefore included, 23 living independently in their own homes and 22 living in care homes. There were three specialist homes for the elderly mentally infirm $(n=14)$ and three residential homes (non-specialist, $n=8$ ).

Mean age was 74.3 years old, with 23 men and 22 women and with no significant age or gender differences between the groups (Table 1). The duration of illness ranged from 2 years to 68 years, with mean of 22 years (16 years in own home-living group and 30 years in residential home-living group, borderline significance). In $78 \%$ of the participants, onset was at age less than 65 years old, with no significant difference between groups. Three times as many $(72 \%$ v. $28 \%, P<0.01)$ of those living in care homes than those living in their own homes were prescribed more than one psychotropic drug, but although higher by $22 \mathrm{mg}$, the calculated mean chlorpromazine equivalent dosage (using a formula by Woods, 2003) did not differ significantly between groups.

Those in care homes had higher total PANSS scores but not on the positive symptom sub-scale. Their daily-life
Table 1. Differences between the two groups

\begin{tabular}{lcc} 
& $\begin{array}{c}\text { Living in } \\
\text { own home } \\
(n=23)\end{array}$ & $\begin{array}{c}\text { Living in a } \\
\text { care home } \\
(n=22)\end{array}$ \\
& 74.3 & 74.6 \\
Mean age, years & & \\
Gender & 13 & 10 \\
Male & 10 & 12 \\
Female & 16 & 30 \\
Duration of psychosis, years & 21.00 & $38.9^{* *}$ \\
PANSS total score & 7.3 & 9.2 \\
$\quad$ Positive & 5.6 & $14.2^{* *}$ \\
$\quad$ Negative & 7.9 & $16.4^{* *}$ \\
$\quad$ General & 25.2 & $17.5^{*}$ \\
MMSE & & \\
Medical morbidity (Burvill; & 4.4 & 5.6 \\
the higher, the worse) & 152.7 & 174.4 \\
Mean daily chlorpromazine & & \\
equivalents, mg & & \\
IADL total score & $11.0^{1}$ & $2.82^{* *}$ \\
(the lower, the worse) & $5.48^{1}$ & $0.77^{* *}$ \\
Subscale (day to day) & $5.52^{1}$ & $2.00^{* *}$ \\
Physical maintenance & $2^{2}$ & 3 \\
Dementia (clinical diagnosis), $n$ & & \\
\hline
\end{tabular}

${ }^{*} P<0.05,{ }^{*} P<0.01$

PANSS, Positive and Negative Symptom Score; MMSE, Mini Mental State

Examination; IADL, Instrumental Activities of Daily Living Scale.

1. Slight discrepancy in total score added from sub-scales owing to missing data

( 2 cases) from one sub-scale in the community group.

2. One case missing data.

activities were reduced across both basic and complex sub-scales. On the Burvill scale, medical morbidity did not differ between groups. Using the MMSE, cognition was significantly lower in the care home group but the overall rate of dementia defined clinically (ICD-10) did not differ.

\section{Discussion}

The strengths of the study are its delineation of all individuals from a single catchment area, low refusal rate and groups well-matched by age. Its limitations include its small size and difficulty in generalising to other services. With these limitations, this study suggests markedly higher morbidity and disablement among older people with chronic schizophrenia living in care homes compared with those living in their own homes. However, the original hypothesis was only partly supported. Individuals in care homes had higher levels of psychiatric symptomatology but this was largely from negative or deficit symptoms rather than positive ones. Their higher scores on the 'general' sub-scale of the PANSS may have been owing to poorer cognition as this sub-scale includes items such as disorientation and confusion. People in care homes had far greater impairment in their daily-life activities, which included basic tasks such as bathing, eating, toileting and food preparation as well as more complex daily tasks. Four participants scored 0 on the IADL scale, 
suggesting total reliance on carers for all of their needs. This disability was not accounted for by those in care homes having more medical morbidity as we had hypothesised. Rather, the combination of deficit symptoms and poor cognition appeared to be responsible. Poor cognition with or without dementia is reported in older people with schizophrenia (Harvey et al, 1999). Thus the disablement of care home residents seems likely to be intrinsic to their psychotic disorder, although the effects of long-term institutionalisation cannot be ruled out as an additional factor.

There exists no national service framework that would adequately address the needs of older people with psychosis (Royal College of Psychiatrists, 2002). The two probably most relevant here are not directly concerned with this group - the National Service Framework for Older People (Department of Health, 2001) focused on dementia and depression, and the National Service Framework for Mental Health (Department of Health, 1999) on adults of working age. Considering the complex handicaps arising from their disorder, detailed care planning and review by specialist psychiatric services are imperative for older people with schizophrenia residing in care homes. Despite this, few of those in care homes that took part in this study received input from any member of the Old Age Psychiatry Community Mental Health Team other than the consultant, whereas a majority of those in their own homes received some input from those services. It is not known whether this is typical of other services or not, but it warrants further research. What also need to be examined are the pathways of entry into care homes among this population group.

\section{Declaration of interest}

None.

\section{References}

BURVILL, P.W, MOWRY, B. \& HALL,W. D. Advances in Psychiatric Treat, 10, (1990) Quantification of physical illness 27-34.

in psychiatric research in the elderly.

International Journal of Geriatric

Psychiatry, 5, 161-170.

DEPARTMENT OF HEALTH (1999)

National Service Framework for Mental

Health: Modern Standards and Service

Models. Department of Health.

DEPARTMENT OF HEALTH (2001)

National Service Framework for Older

People. Department of Health.

FOLSTEIN, M. F., FOLSTEIN, S. E. \&

MCHUGH, P. R. (1975) 'Mini-Mental

State': a practical method for grading

the cognitive state of patients for the

clinician. Journal of Psychiatric

Research, 12, 185-198.

HARVEY, P. D., STERMAN, J. M., RICHARD, C., et al (1999) Cognitive decline in later life schizophrenia: A longitudinal study of geriatric

chronically hospitalised patients.

Biological Psychiatry, 45, 32-40

JOLLEY, D., KOSKY, N. \& HOLLOWAY, F. (2004) Older people with longstanding mental illness: the graduates.

KAY, S. R., FISZBEIN, A.\& OPLER, L. A

(1987) The Positive and Negative Syndrome Scale for schizophrenia. Schizophrenia Bulletin, 13, 261-276.

LAWTON, M. P. \& BRODY, E. M. (1969) Assessment of older people: Selfmaintaining and instrumental activities of daily living. Gerontologist, 9, 179186.

MCNULTY, S.V., DUNCAN, L., SEMPLE, M., et al (2003) Care needs of elderly people with schizophrenia. British Journal of Psychiatry, 182, 241-247.

ROYAL COLLEGE OF PSYCHIATRISTS (2002) Caring for People who Enter Old Age with Enduring or Relapsing Mental Illness. College Report CR110, Royal College of Psychiatrists.

WOODS, S.W. (2003) Chlorpromazine equivalent doses for the newer atypical antipsychotics. Journal of Clinical Psychiatry, 64, 663-667.

WORLD HEALTH ORGANIZATION (1993) The ICD-10 Classification of Mental and Behavioural Disorders. WHO.

Emily Clancy 4th Year Medical Student, University of Manchester, *Robert C. Baldwin Department of Old Age Psychiatry, Edale House, Manchester Mental Health and Social Care NHS Trust, Manchester Royal Infirmary, Oxford Road, Manchester M13 9BX, UK, email: robert.c.baldwin@ manchester.ac.uk

WAQQAS AHMAD KHOKHAR, IMRAN HAMEED, MOHAMMED MUBASHIR ALI,

JAVARIA SADIQ AND PETER BOWIE

\section{To trust or not to trust? Faith issues in psychopharmacological prescribing}

\section{AIMS AND METHOD}

To ascertain attitudes, awareness, knowledge and variations in prescribing habits of psychiatrists when addressing issues of faith, culture and dietary requirements (in keeping with the General Medical Council's and the Royal College of Psychiatrists' guidelines), and how these may affect the trust in doctorpatient relations. We undertook a cross-sectional postal survey aimed at clinicians in South West Yorkshire Mental HealthTrust.

RESULTS

We obtained 38 responses $(40 \%$ of the total number of questionnaires sent out) from two mailshots. Although the majority of respondents indicated that they were aware of the presence of potentially forbidden animal-derived ingredients in medication, only half expressed the view that a discussion regarding the above should take place prior to prescribing such medication.

\section{CLINICAL IMPLICATIONS}

Diversity training combined with taking a genuine interest in patients' wishes will not only minimise 'mistrust' but also facilitate prescribing in a therapeutic relationship.
'Patients must be able to trust doctors with their lives and well being. To establish that trust doctors must respect patient's autonomy and patients must be given sufficient information in a way that they can understand and are able to exercise their right to make informed decisions about their care. For example, patients may need more information to 